\title{
Cross-Sectional Study into the Costs and Impact on Family Functioning of 4-Year-Old Children with Aggressive Behavior
}

\author{
Maartje A. Raaijmakers • Jocelyne A. Posthumus • \\ Ben A. van Hout • Herman van Engeland • \\ Walter Matthys
}

Published online: 3 March 2011

(C) The Author(s) 2011. This article is published with open access at Springerlink.com

\begin{abstract}
Early-onset aggressive behavior is known for its negative developmental consequences, and the associated high costs for families, the health care system and wider society. Although the origins of aggressive behavior are to be found in early childhood, the costs incurred by aggressive behavior of young children have not been studied extensively. The present study aimed to investigate whether preschool children with a high level of aggressive behavior already differ in the generated amount of costs and impact on family functioning from children with lower levels of aggressive behavior. A population-based sample of 317 preschool children was divided into four groups with different levels of aggression (moderate, borderline, clinical). Parents filled out questionnaires to assess service use (lifetime and past 3 months) and impact on family functioning. Over the past
\end{abstract}

Electronic supplementary material The online version of this article (doi:10.1007/s11121-011-0204-y) contains supplementary material, which is available to authorized users.

\footnotetext{
M. A. Raaijmakers · J. A. Posthumus $\cdot$ H. van Engeland ·

W. Matthys

Department of Child- and Adolescent Psychiatry,

Rudolf Magnus Institute for Neuroscience,

University Medical Centre Utrecht,

Utrecht, The Netherlands

B. A. van Hout

Julius Centre for Health Sciences and Primary Care,

University Medical Centre Utrecht,

Utrecht, The Netherlands
}

M. A. Raaijmakers $(\bowtie)$

Department of Developmental Psychology, University of Utrecht, P.O. Box 80140, 3508 TC Utrecht, The Netherlands

e-mail: M.A.J.Raaijmakers@uu.nl
3 months as well as over the first 4 years of life, children with a clinical level of aggression were more costly than children with a low level of aggression (mean total costs over the past 3 months: low $=€ 167,05$ versus clinical $€=1034,83$ and mean lifetime costs: low $€=817,37$ versus clinical $€=$ $1433,04)$, due to higher costs of services used by the child. In addition, families of children with a borderline or clinical level of aggressive behavior reported more impairment in their daily functioning than families of children with lower levels of aggression. The findings demonstrate that a high level of aggressive behavior results in high costs and impaired family functioning in the preschool years already.

Keywords Costs of service use - Aggressive behavior . Preschoolers

\section{Introduction}

Disruptive Behavior Disorders (DBD), a term which covers both oppositional defiant disorder (ODD) and conduct disorder (CD) (American Psychiatric Association 2000) are known for their negative developmental outcomes; e.g., high school drop out, delinquency, substance use dependence, personality disorders, and unemployment (Maughan and Rutter 2001). These negative outcomes have large financial implications for families of children with DBD, the (mental) health care system and wider society.

Several studies have investigated the financial consequences of DBD in school-aged children and adolescents. In general, these studies reported substantially higher costs of children with conduct problems when compared to their normally developing peers (Foster et 
al. 2005; Knapp et al. 1999; Scott et al. 2001). These high costs were mainly due to criminal activities, and increased utilization of health, social, and educational services. Since patterns of service use tend to be stable over time (Lavigne et al. 1998; Leventhal et al. 2000), these patterns may predict utilization of services at later ages (Vostanis et al. 2003). In addition, parents of children with conduct problems often report using more services due to their children's behavior than parents of typically developing children (Knapp et al. 1999).

It is important to investigate whether service use and costs of young children with aggressive behavior are already high at an early age. Since high levels of aggressive behavior tend to be stable and persistent over time (Frick and Loney 1999; Shaw et al. 2005; Tremblay et al. 2004), effective preventive interventions for these children may have long-term benefits and the costs of such interventions may be outweighed by the long-term savings. Two studies have been conducted in young children with a relatively large age range (Lavigne et al. 1998; Romeo et al. 2006) and revealed that children referred for antisocial behavior as well as children with externalizing problems were significantly related to increased use of services, resulting in high costs. Additionally, it was reported that these children imposed a substantial burden on their families; e.g., by extra time their parents spent on household tasks (Romeo et al. 2006). However, these studies did not differentiate in level of aggression, nor look at a specific age group.

\section{Aims of the Study}

The present study aimed to examine whether 4-year-old children with high levels of aggressive behavior differ in their rate of service use and associated costs, and in the burden on the family compared to children with lower levels of aggression. To investigate whether aggressive preschool children already generate high costs, we assessed service use and estimated costs over the past 3 months and the first 4 years of life of children who ranged from low to clinical levels of aggression. We hypothesized that children who showed high levels of aggressive behavior and their parents would use more services, resulting in higher costs than children with normative levels of aggression and their parents. Impairments in daily functioning of the parents due to the behavior of the child (e.g., extra time needed for daily household tasks, absenteeism at work, and damage done by the child) were also assessed. In this regard, we hypothesized that parents of children with high levels of aggressive behavior were more impaired in their daily functioning than parents of children with a low level of aggression.

\section{Methods}

\section{Participants}

Data were collected on 317 children who were enrolled in a study into the preventive effect of an intervention for parents of preschool children with aggressive behavior. Children were selected from a Dutch population-based sample in the province of Utrecht. The addresses of the children were acquired by the Office for Screening and Vaccination. All recruited children were born either in 2000 or 2001 and were 4 years old at the time of assessment. Children's level of aggression was measured by the Child Behavior Checklist $1 \frac{1}{2-5}$ (CBCL) Aggressive Behavior scale (Achenbach and Rescorla 2000; Dutch version by Verhulst \& Van der Ende). This scale consists of 19 items (e.g., "hits others" and "often has temper tantrums"). Parents circle the answer which fits the behavior of their child: "never", "sometimes" or "always." In this study, we wanted to compare the costs of children with different levels of aggression, and therefore children were divided into four groups. The two groups of children with higher levels of aggressive behavior were classified according to CBCL norms. The Borderline Range (93rd to 97th percentile) contains raw scores ranging from 21 to 23 (i.e., borderline group), and the Clinical Range of the CBCL includes scores of 24 and higher $(\geq 97$ th percentile; i.e., clinical group). Children with different levels of aggression, and therefore children with lower levels of aggression were included in two other groups. Based on previous studies into the prevention of disruptive behavior, we applied somewhat similar criteria to identify children at risk (e.g., Lochman and Wells 2004; Tremblay et al. 1995). Children with an Aggressive Behavior score below the 80th percentile (raw scores ranging from 0 to 15 ) were considered to have a low level of aggressive behavior; therefore, these children were classified as "low." Children with scores ranging from 16 to 20 (i.e., scores above the 80th and below the 93rd percentile) were classified as "moderate." We assumed that those children would show more problematic behavior than the low group, but less than groups with higher levels of aggression. Descriptives of these four groups are displayed in Table 1. Although the child's age differed significantly between the groups $(F(3,316)=5.432$, $p=.00$ ), this difference of less than 2 months between the low and clinical group was not considered relevant. In addition, it should be noted that the population studied was very highly educated when compared to the general Dutch population.

Procedure

Voluntary written informed consent was obtained from the participating families. A set of questionnaires was mailed to 
Table 1 Sample characteristics by group

\begin{tabular}{|c|c|c|c|c|}
\hline CBCL Percentile & $\begin{array}{l}\text { LOW } \\
<80 \text { th } \\
(n=189) \\
M(S D)\end{array}$ & $\begin{array}{l}\text { MOD } \\
\geq 80 \text { th to } \leq 93 \text { rd } \\
(n=56) \\
M(S D)\end{array}$ & $\begin{array}{l}\text { BORD } \\
\geq 93 \text { rd to } \leq 97 \text { th } \\
(n=25) \\
M(S D)\end{array}$ & $\begin{array}{l}\text { CLIN } \\
\geq 97 \text { th } \\
(n=47) \\
M(S D)\end{array}$ \\
\hline \multicolumn{5}{|l|}{ Child } \\
\hline Gender ( $\%$ boys $)$ & 61.4 & 57.1 & 72.0 & 78.7 \\
\hline Age (months) * & $51.8(2.27)$ & $51.2(2.45)$ & $51.5(3.24)$ & $50.1(3.26)$ \\
\hline IQ & $109.3(11.90)$ & $108.6(9.77)$ & $108.9(10.74)$ & $105.1(11.11)$ \\
\hline Aggressive behavior & $6.8(4.52)$ & $18.0(1.52)$ & $22.0(0.89)$ & $27.8(3.66)$ \\
\hline \multicolumn{5}{|l|}{ Parent } \\
\hline \multicolumn{5}{|l|}{$\mathrm{N}$} \\
\hline Mother & 188 & 56 & 25 & 46 \\
\hline Father & 176 & 48 & 23 & 44 \\
\hline \multicolumn{5}{|l|}{ Age (years) } \\
\hline Mother & $35.6(4.18)$ & $35.0(6.25)$ & $35.3(3.59)$ & $34.1(4.48)$ \\
\hline Father & $38.0(4.75)$ & $37.1(4.60)$ & $37.6(4.20)$ & $37.4(6.01)$ \\
\hline \multicolumn{5}{|l|}{ Education (\%) } \\
\hline Primary & 1.1 & - & - & 2.1 \\
\hline Secondary & 3.2 & 3.7 & 8.0 & 4.3 \\
\hline Intermediate vocational & 28.9 & 42.6 & 20.0 & 29.8 \\
\hline Higher vocational & 34.8 & 31.5 & 28.0 & 38.3 \\
\hline University & 32.1 & 22.2 & 44.0 & 25.5 \\
\hline
\end{tabular}

the parents. Parents received a monetary reward of $€ 20$,- for their participation. The study was approved by the Medical Ethical Review Committee of the Utrecht University Medical Center.

\section{Measures}

\section{Data on Service Use}

Data on service use of the child due to aggressive behavior problems over the past 3 months and over the first 4 years of life were collected retrospectively. Additional data on service use of the parents in the past 3 months were also collected. Parents were asked to report which types of services were used by their children and themselves and about the frequency of consultations. Nineteen different service types were categorized into the following domains: medical care (General Practitioner (GP), specialist services, physiotherapist, speech therapist, language center, health visitor and alternative medicine), mental health care (child psychologist, psychologist psychiatrist, mental health services (day treatment or outpatient treatment)), youth care (regional child care; i.e. community youth care, social work, service for the learning disabled, medical day nursery, special needs day nursery, child care \& protection board) and educational care (educational services) of the children. The use of medical care (GPs, specialist services, company doctor, physiotherapist, alternative medicine), mental health care (child psychologist, psychologist, psychiatrist, mental health services) and community care (social work) of the parents over the past 3 months was also assessed. Service use was assessed in different manners over 4 years and 3 months. Over 3 months, parents were asked to fill out the number of consultations. Over 4 years, parents reported the frequencies of utilization of services in four categories, $0-5,6-10,11-15$, and more than 15 consultations. In our calculations we used the absolute values $3,8,13$, and 16 for these four categories respectively.

\section{Cost Calculation}

Service cost estimates were based on figures published in Oostenbrink et al. (2004), on information from health insurance companies, personal communication with service providers and the Internet. These service cost estimates include the total amount of costs of the service used; i.e., salary, housing, materials and all other costs associated with service use. All costs were calculated in Euros at 2004 price levels (see Appendix A). To generate service costs for each participant, cost estimates for each service type were combined with our data on service use. Only mother reports on child service use were included in this study. Service use by parents themselves was reported for mothers and fathers separately. 


\section{Questionnaire on Work and Costs}

To collect information on impairment in daily functioning of the parents, a questionnaire based on the Health and Labour Questionnaire (HLQ) (Hakkaart-van Roijen and Essink-Bot 1999; Van Roijen et al. 1996) was adapted (see Appendix B). Employment status, absenteeism at work due to the child's behavior, extra time and help needed for housekeeping, for activities with the child and for doing chores were assessed. In addition, the costs of damage done by the child were assessed. The questionnaire consisted of 12 questions that were asked about the past 3 months or the past 2 weeks. Both mothers and fathers filled out this questionnaire.

\section{Data Analysis}

Separate analyses were conducted for the costs of lifetime service use of the child and service use over the past 3 months of both child and parents; both means and medians were reported and tested. For the analyses on service use of the child and damage done by the child the mothers' report was used, except for the children whose father was the primary caretaker $(n=2)$. The Questionnaire on Work and Costs was analyzed for mothers and fathers separately, using $\chi^{2}$ analyses and ANOVAs for the different variables, followed by post hoc Bonferroni tests.

\section{Results}

\section{Service Use-Child}

Data reported on service use are often highly skewed, because only a small number of participants may use a specific type of service very often, whereas a substantial number of participants may have no contact with this service type at all. Therefore, in the appendices, the number of parents and children who actually received services is depicted, as well as the service costs for this group of parents and children. Appendix C and D present utilization rates and service costs for all groups of children over the past 3 months and the first 4 years of life, respectively. Over the past 3 months, medical care was used by the largest number of children in all groups, but did not account for the highest costs. Although not many children used services other than medical care, the highest service costs for the group of children with a low level of aggression were caused by mental health care, and in the groups with higher levels of aggressive behavior youth care accounted for the highest costs. Due to the small number of participants who used services, analyses on separate service categories were not meaningful. Therefore, the total costs (an addition of the costs of medical, mental health, youth, and educational care) per group over 3 months were compared using one-way ANOVA. This analysis revealed a significant effect, $F(3,177)=4.145, p=.01$, and was followed by a Bonferroni post hoc test, which yielded a significant effect for the group with a low level of aggression versus the clinical group $(p=.00)$. These findings indicate that the group of children who showed a clinical level of aggressive behavior was significantly more costly over the past 3 months than the group with a low level of aggression. In addition, a univariate ANOVA followed by a post hoc Bonferroni test was conducted on the total frequency of service use. A significant difference in the frequency of service use between the group with a low level of aggressive behavior and the group with a clinical level of aggression became apparent, $F(3,177)=$ 3.467, $p=.02$; Bonferroni: $p=.01$. The clinical group visited services significantly more often than the group of children with a low level of aggression. With respect to the demographic variables, no associations between the amount of costs over 3 months and parent or child variables were found.

Appendix D displays utilization rates and service costs over the child's whole life. Over 4 years, medical care was the service category that was used by the largest number of participants again, and it was also the category of service that was used most often. In contrast to the findings over the past 3 months, in the first 4 years of life medical care was for almost all groups the service category that yielded the highest costs. In the group of children with a moderate level of aggression, costs were almost equally divided over the services categories. Only in the clinical group were the highest costs clearly due to a category other than medical care, namely youth care. Again, only a small number of participants used services other than medical care. Hence, the total costs per group over 4 years (see Appendix D) were compared using one-way ANOVA. This analysis revealed a significant effect, $F(3,282)=4.694, p=.00$. The Bonferroni post hoc test also yielded a significant effect for the low group versus the clinical group $(p=.00)$. These results show that over 4 years, the group of children with a clinical level of aggression generated more service costs than the group with a low level of aggression. Again, the total frequency of service use was analyzed and this yielded a significant difference between the group of children with a low level of aggression and the group of children with a clinical level of aggression, $F(3,284)=$ 4.536, $p=.00$; Bonferroni: $p=.00$. The clinical group used services more often than the group of children with low levels of aggression. To take into account that a lot of children did not use services at all and to provide a more complete description of the data, medians were also tested 
with Kruskall-Wallis tests, followed by Mann-Whitney U tests and post hoc Bonferroni tests. Results found were similar to the results of the ANOVA performed previously (medians past 4 years: $\mathrm{LOW}=580,60 ; \mathrm{MOD}=640,00$; $\mathrm{BOR}=681,60 ; \mathrm{CLIN}=915,60 ; \chi^{2}=10.281, p=.02$; Bonferroni low versus clinical: $p=.02$ ). With respect to the demographic variables, associations between the amount of costs and IQ of the child and age of the mother were found; the lower the IQ of the child $(r=.00)$, and the lower the age of the mother $(r=.04)$, the higher the generated amount of costs over 4 years.

\section{Service Use-Parents}

Service use of mothers and fathers in the past 3 months was assessed. For both mothers and fathers in all groups medical care was the service which was used by the largest number of participants. However, for both parents no significant differences between the groups in total costs and frequency of service use were found.

\section{Damage}

Parents were also asked to report whether their child had damaged or destroyed objects in the past 3 months (see Appendix E). A significant relation between destroying or damaging objects like toys, plates, furniture, drawings, vases, several household goods and the level of aggression was found. The analysis revealed that more children in the clinical group had damaged or destroyed objects than children in the low, moderate, and borderline groups. The monetary value of the objects the child damaged or destroyed as well as the number of physical injuries caused by the child did not differ between the groups.

\section{Total Costs: Child, Parents and Damage}

Next, total costs of the child were computed by adding up service utilization costs of the child and both parents, and the costs of damage done by the child over the past 3 months (see Appendix C). A univariate ANOVA revealed that the groups significantly differed in total costs, $F(3,316)=7.198, p=.00$. A post hoc Bonferroni test showed that the clinical group had significantly higher costs than the low and moderate group and the difference in costs between the clinical and borderline group was marginally significant, with the clinical group being more costly (post hoc Bonferroni: clinical versus low and moderate group: $p=.00$ ). Again medians were also tested with Kruskall-Wallis tests, followed by Mann-Whitney U tests and post hoc Bonferroni tests. Results found were similar to the results of the ANOVA performed previously (medians past 3 months: $\mathrm{LOW}=61,25 ; \mathrm{MOD}=165,40$;
$\mathrm{BOR}=178,60 ; \mathrm{CLIN}=310,60 ; \chi^{2}=19.368, p=.00$; Bonferroni low versus clinical: $p=.00$ ).

In order to check whether the costs found were actually due to antisocial behavior, rather than the fact that these problems occur in more disadvantaged families who might use more services regardless of whether their children are antisocial, a multiple regression analysis was performed. The educational level of the parents (which was used as an indicator of SES in this study) was taken into account to see whether the costs found were a consequence of antisocial behavior or markers of general social deprivation. Total costs over 3 months were entered as the dependent variable and the four CBCL groups and education were entered separately as independent variables in the analysis; $B_{\mathrm{CBCL}}=.21, F(1,315)=13.91, p=.00 ; \mathrm{R}^{2}$ change $=.042$ and $B_{\text {education }}=-.04, F(1,311)=.582, p=.45 ; \mathrm{R}^{2}$ change $=.002$. The results of this analysis revealed that the costs found are truly costs of antisocial behavior; the influence of education of the parents was not significant. In addition, it became apparent that the influence of social status was very small; much smaller than the influence of aggressive behavior.

Work

Results of the analyses on work are shown in Appendix E. A chi-square test of independence was performed to examine the relationship between the level of aggression (the four groups) and employment status. A significant relation between group and not being able to have a job or having to work part-time due to the child's aggressive behavior was found for mothers. The largest number of mothers who were unable to work full-time due to the behavior problems of their child was found in the clinical group. In contrast, not one father reported that he was not able to work or had to work part-time due to the child's aggressive behavior.

Absenteeism at work differed significantly between the groups for both mothers and fathers; mothers and fathers of children in the clinical and borderline groups were more often needed at home due to the behavior problems of their children than mothers of children in the moderate and low group. In addition, a significant difference between the groups in absenteeism at work due to visiting services with the child was found for mothers. Mothers in the clinical group were more often needed for visiting services with their children than mothers of children with a low level of aggression. Parents were also asked whether they were hampered or functioned less optimally due to their child's behavior problems while working. The analysis revealed that being hampered at work or functioning less optimally was significantly related to group for both parents. Parents in the borderline group reported to be hampered at work most often, followed by parents in the clinical group. 
Impairment in Family Functioning

Results of the analyses on family functioning are depicted in Appendix E. Regarding impairments in daily functioning at home, a significant difference in the hours spent on doing household tasks (e.g., cleaning or cooking) was revealed for mothers. Mothers of children in the clinical group spent more hours on household tasks than mothers of children with lower levels of aggression. For fathers, a significant difference in time spent on doing groceries was found. Fathers in the borderline group spent more time on doing groceries than fathers in the moderate group did. With respect to the mothers who were not able to do their household tasks due to the aggressive problems of their child, mothers in the borderline group received the most paid help from others (e.g., from a daily help), significantly more than the mothers in the groups with lower levels of aggression. Fathers in the clinical group received significantly more help from family members, relatives, or neighbors than fathers of children with a low level of aggression. In addition, parents were asked to report whether they had done their household tasks, groceries, chores, and activities with their child in the past 2 weeks and whether they were hindered by the aggressive behavior problems of their child while carrying out these activities. For mothers, significant relations between group and household tasks, doing groceries, doing chores, and activities with their children were found. Fewer mothers in the clinical group had done household tasks and chores, groceries were less often done by mothers in the moderate group, and activities with the children were less often carried out by mothers in the borderline group than by mothers in the other groups. No significant relations between group and carrying out any of these tasks were found for fathers.

Hindrance experienced by parents due to the aggressive behavior of their child while performing these tasks was significantly related to the level of aggression of the child, for both mothers and fathers. On all of these tasks or activities, larger percentages of mothers and fathers of children in the clinical group reported to be hindered by their children's behavior problems than did mothers and fathers in the groups of children with lower levels of aggressive behavior. The smallest percentages of mothers and fathers who experienced hindrance were found in the groups of mothers and fathers of children with a low level of aggression.

\section{Discussion}

This study of 4-year-old children with aggressive behavior tested hypotheses regarding impairments in family function- ing and costs of service use of both the child and its parents. As expected, already at 4 years of age, differences between children with high and low levels of aggression in both costs of service use (over the past 3 months as well as the first 4 years of life), and family functioning became apparent. Children with a high (clinical) level of aggression were found to be more costly than children with a low level of aggression, due to higher costs of services used by the child. In addition, parents of children with higher levels of aggression (borderline and clinical) showed more impairment in daily functioning than parents of children with lower levels of aggression.

Although several studies have investigated family functioning and costs of children who were referred to mental health services for severe antisocial behavior or a diagnosis of $\mathrm{CD}$ with an age range from 3 to 10 years (Knapp et al. 1999; Romeo et al. 2006), to our knowledge this is the first study that assessed both impact on family functioning and costs of service use in a group of 4-yearold children with different levels of aggressive behavior in a large population-based sample. Overall, the results of this study were fairly consistent regarding impairment in daily functioning and costs of service use; differences were mainly seen between children with a high level of aggression (borderline and clinical group) and children with a low level of aggression. This complements literature demonstrating that children who do not fully meet the criteria for a disorder but who show a large number of aggressive behavior problems or subclinical levels of aggression might experience negative and costly consequences already (Angold et al. 1999).

Notwithstanding the fact that data over 4 years might be subject to recall bias, the findings on service use over 4 years correspond with the results found over 3 months. Regarding the costs of service use over the past 3 months, our results confirmed our hypotheses and were in line with other studies (Lavigne et al. 1998; Romeo et al. 2006); the highest costs of service use were found for the group of children with clinical levels of aggression.

Interestingly, highly aggressive children used more youth care services than children with lower levels of aggression. This might be due to limited recognition of young children's psychopathology by GPs (Sayal and Taylor 2004; Zwaanswijk 2005). As illustrated by the finding that only children who show clinical levels of aggression incurred high costs in youth care, it might be that GPs refer 4-year-old children with more severe aggressive behavior problems to youth care services first. At such a young age, GPs might tend to interpret aggressive behavior in terms of parenting problems, whereas older children and adolescent will be directly referred to mental health services.

Contradictory to our hypothesis, no differences in service use and costs of both mothers and fathers were found between the groups. Although parents of children 
with borderline and clinical levels of aggression reported impairments in their daily functioning, they did not seek help or use services more often than parents of children with lower levels of aggression did, in contrast with the findings of Knapp et al. (1999). This absence of increased service use of the parents of aggressive preschoolers might be due to the young age of this group of children. The aggressive behavior of the child has a direct effect on the daily functioning of the family, whereas more frequent service use of the parents might be a more indirect effect. If a high level of aggressive child behavior becomes an entrenched pattern over time, parental service use might increase as a consequence of the child's behavior problems.

The findings on impairment in daily functioning of the parents reflect the problems that parents of children with highly aggressive behavior experience. It is shown that the impact of preschool children with aggressive behavior on their families is large. Parents do not only carry the burden of the behavioral problems of their child and its negative consequences, but they experience additional difficulties in their own functioning at work, in their housekeeping and activities with their children. Mothers were especially hindered in their daily functioning. With respect to doing household tasks, a difference between mothers and fathers of children with aggressive behavior was found. Although fathers also reported hindrance while doing household tasks and activities with their children, fathers were still able to carry out these tasks and activities, unlike the mothers. This might be a consequence of the conventional role pattern of men and women in the Netherlands; in most Dutch families wages are mainly earned by full-time working fathers, while most part-time working mothers carry the responsibility for the children and housekeeping (Portegijs and Keuzenkamp 2008).

This study has certain limitations that are important to acknowledge in interpreting the results. First, data on service use as well as data on child behavior were collected from a single source, the primary caregiver, mostly the mother. Teacher ratings of antisocial behavior were unavailable due to the Dutch school system, in which it is only mandatory to attend school from age 5 onwards, and could therefore not be used in this study. Using parental ratings for both variables caused a lack of independence between the dependent and independent variables. In addition, since we relied on parent-reported data only, several different explanations for high rates of service use can be given. A first explanation could be that parents who use services for their children in a high frequency might be more inclined to rate their children's behavior as (more) problematic. Another explanation might be that parents who are high-rate endorsers on many types of instruments rated their children's behavior as more aggressive and reported greater service utiliza- tion and damages. A final possibility could be that children who really are showing a high level of aggression at age 4 were also involved in a greater amount of service use and damaged more objects from birth to age 4. Due to the uncertainty of the origin of high levels of aggressive child behavior and consequently higher cost of service use, the results of this study should be interpreted cautiously.

Second, our measure of service use was a self-report instrument for parents and data were collected retrospectively. Therefore, data might have been influenced by parental and recall biases, especially the data on service use over the first 4 years of life of the child. In future research, the use of additional data sources, such as administrative records of services, might help in preventing these biases. In addition, to provide a comprehensive picture of the costs of children with aggressive behavior, costs associated with loss of productivity of the parents and of service delivery should also be taken into account (e.g., travel costs, administrative costs and the child's future earnings). Third, in all groups more boys than girls were included. Although no differences in gender ratio between the groups were found, the results presented here are mainly relying on data from boys. Despite the fact that the dominance of boys with respect to aggressive behavior problems is well known (Archer and Côté 2005), by using larger groups, it should be possible to include more girls in the study and to make inferences about their service use and costs. Fourth, our sample consisted of highly educated parents who had children at a relatively older age. Despite our efforts, we did not succeed in involving less educated families in this study. The number of parents who received higher vocational or university education was twice as high in this study as in the general population in the Netherlands (CBS, Statline 2006). This might have introduced bias to our data on service use, because children with the most severe aggressive behavior problems often come from less educated and relatively young parents (Côté et al. 2006; Nagin and Tremblay 2001). Therefore, due to the overrepresentation of highly educated people, the effects found in this study might have been greater if a more disadvantaged sample had been used. Fifth, the results presented here are only applicable to the Dutch health care system. In the Netherlands, not only health care but also social services and youth care are available for the whole population, and there are no financial barriers to use services. Therefore, these findings cannot be generalized to countries with other health care or social service systems. An additional limitation is that not all children in our sample went to school, which might have caused an underestimation of the costs of educational care. In the Netherlands it is mandatory for children to attend school from age 5 onwards, but almost all children go to school at age 4 . Therefore, we 
assume that the children who participated in this study probably attended school for only 3 months. Since educational costs are likely to increase as children grow older, it is important to investigate educational costs longitudinally in future research.

This study extends the finding that aggressive behavior in school-aged children generates high costs (Foster et al. 2005; Knapp et al. 1999; Scott et al. 2001) in that a high level of aggressive behavior at 4 years of age already incurs high costs and has a large impact on the family in the Netherlands. Hence, a decrease in aggressive behavior at a young age might lead to a decrease in costs for the child, the family and wider society. If this decrease of aggressive behavior does not occur, the risk for DBD increases and costs will rise over time due to high rates of service use for the treatment of psychiatric disorders, delinquency, incarceration, and unemployment. Recently, evidence-based interventions and prevention programs have gained attention. There is evidence that these programs effectively reduce aggressive problem behaviors (Conduct Problems Prevention Research Group 1999; Hutchings et al. 2007; McCart et al. 2006; Shaw et al. 2006). Consequently, early and accurate identification of children with high levels of aggressive behavior who might be at risk for the development of DBD and the investment of delivering these programs with fidelity will result in large savings on the long term. The finding that children with high levels of aggressive behavior already generate high costs at 4 years of age, and that these costs are likely to increase as these children grow older, due to, for example, the need for educational services or criminal activities, indicates that prevention programs should be aimed at children in the preschool period.

Acknowledgements We are grateful to the parents and children who participated in this study. We are also grateful to Rianne Maillé and Iris de Kruif for their help in data preparation and collection. The research project was funded by ZonMw Prevention (\#2620.0001).

Open Access This article is distributed under the terms of the Creative Commons Attribution Noncommercial License which permits any noncommercial use, distribution, and reproduction in any medium, provided the original author(s) and source are credited.

\section{References}

Achenbach, T. M., \& Rescorla, L. A. (2000). Manual for the ASEBA preschool forms and profiles. Burlington: University of Vermont, Research Center for Children, Youth \& Families.

American Psychiatric Association. (2000). Diagnostic and statistical manual of mental disorders - text revision (4th ed.). Washington, DC: Author.

Angold, A., Costello, E. J., Farmer, E., Burns, B. J., \& Erkanli, A. (1999). Impaired but undiagnosed. Journal of the American Academy of Child and Adolescent Psychiatry, 38, 129-137.
Archer, J., \& Côté, S. (2005). Sex differences in aggressive behavior: A developmental and evolutionary perspective. In R. E. Tremblay, W. W. Hartup, \& J. Archer (Eds.), Developmental origins of aggression (pp. 425-443). New York: Guilford.

CBS, Statline (2006). http://www.cbs.nl/nl-NL/menu/cijfers/statline/ informatie/.

Conduct Problems Prevention Research Group. (1999). Initial impact of the Fast Track prevention trial for conduct problems: I. The high risk sample. Journal of Consulting and Clinical Psychology, 67, 631-647.

Côté, S. M., Vaillancourt, T., LeBlanc, J. C., Nagin, D. S., \& Tremblay, R. E. (2006). The development of physical aggression from toddlerhood to pre-adolescence: A nationwide longitudinal study of Canadian children. Journal of Abnormal Child Psychology, 34, 71-85.

Foster, E. M., Jones, D. E., \& the Conduct Problems Prevention Research Group. (2005). The high costs of aggression: Public expenditures resulting from conduct disorder. American Journal of Public Health, 95, 1767-1772.

Frick, P. J., \& Loney, B. R. (1999). Outcomes of children and adolescents with conduct disorder and oppositional defiant disorder. In H. C. Quay \& A. Hogan (Eds.), Handbook of disruptive behaviour disorders (pp. 507-524). New York: Plenum.

Hakkaart-van Roijen, L., \& Essink-Bot, M. L. (1999). Manual health and labour questionnaire (in Dutch). The Netherlands: Institute of Medical Technology Assessment, Erasmus University Rotterdam.

Hutchings, J., Bywater, T., Daley, D., Gardner, F., Whitaker, C., Jones, K., et al. (2007). Parenting intervention in Sure Start services for children at risk of developing conduct disorder: Pragmatic randomised trial. British Medical Journal, 334, 678-685.

Knapp, M., Scott, S., \& Davies, J. (1999). The cost of antisocial behaviour in younger children. Clinical Child Psychology and Psychiatry, 4, 457-473.

Lavigne, J. V., Binns, H. J., Arend, R., Rosenbaum, D., Christoffel, K. K., Hayford, J., et al. (1998). Psychopathology and health care use among preschool children: A retrospective analysis. Journal of the American Academy of Child \& Adolescent Psychiatry, 37, 262-270.

Leventhal, T., Brooks-Gunn, J., McCormick, M. C., \& McCarton, C. M. (2000). Patterns of service use in preschool children: Correlates, consequences and the role of early intervention. Child Development, 71, 802-819.

Lochman, J. E., \& Wells, K. C. (2004). The Coping Power Program for preadolescent aggressive boys and their parents: Outcome effects at the 1-year-follow-up. Journal of Consulting and Clinical Psychology, 72, 571-578.

Maughan, B., \& Rutter, M. (2001). Antisocial children grown up. In J. Hill \& B. Maughan (Eds.), Conduct disorders in childhood and adolescence (pp. 507-552). Cambridge, UK: Cambridge University Press.

McCart, M. R., Priester, P. E., Davies, W. B., \& Azen, R. (2006). Differential effectiveness of behavioral parent training and cognitive-behavioral therapy for antisocial youth: A metaanalysis. Journal of Abnormal Child Psychology, 34, 527-543.

Nagin, D. S., \& Tremblay, R. E. (2001). Parental and early childhood predictors of persistent physical aggression in boys from kindergarten to high school. Archives of General Psychiatry, 58, 389-394.

Oostenbrink, J. B., Bouwmans, C. A. M., Koopmanschap, M. A., Rutten, F. F. H. (2004). Handleiding voor kostenonderzoek; methoden \& standaard kostprijzen voor economische evaluaties in de gezondheidszorg; geactualiseerde versie 2004. Rotterdam: Instituut voor Medical Technology Assessment, Erasmus MC (i.o. College voor Zorgverzekeringen). 
Portegijs, W., \& Keuzenkamp, S. (2008). Nederland deeltijdland: Vrouwen en deeltijdwerk. Den Haag: Sociaal en Cultureel Planbureau.

Romeo, R., Knapp, M., \& Scott, S. (2006). Economic costs of severe antisocial behaviour in children-and who pays it. British Journal of Psychiatry, 188, 547-553.

Sayal, K., \& Taylor, E. (2004). Detection of child mental health disorders by general practitioners. British Journal of General Practice, 54, 348-352.

Scott, S., Knapp, M., Henderson, J., \& Maughan, B. (2001). Financial costs of social exclusion: Follow-up study of antisocial children into adulthood. British Medical Journal, 323, 191-194.

Shaw, D. S., Lacourse, E., \& Nagin, D. S. (2005). Developmental trajectories of conduct problems and hyperactivity from ages 2 to 10. Journal of Child Psychology and Psychiatry, 46, 931-942.

Shaw, D. S., Dishion, T. J., Supplee, L., Gardner, F., \& Arnds, K. (2006). Randomized trial of a family-centered approach to the prevention of early conduct problems: 2-year effects of the Family Check Up in early childhood. Journal of Consulting and Clinical Psychology, 74, 1-9.
Tremblay, R. E., Pagani-Kurtz, L., Mâsse, L. C., Vitaro, F., \& Pihl, R. O. (1995). A bi-modal preventive intervention for disruptive kindergarten boys: Impact through mid-adolescence. Journal of Consulting and Clinical Psychology, 63, 560-568.

Tremblay, R. E., Nagin, D. S., Séguin, J. R., Zoccolillo, M., Zelazo, P. D., Boivin, M., et al. (2004). Physical aggression during early childhood: Trajectories and predictors. Pediatrics, $114,43-50$.

Van Roijen, L., Essink, B. M., Koopmanschap, M., Bonsel, G., \& Rutten, F. (1996). Labor and health status in economic evaluation of health care. Health \& Labor Questionnaire. International Journal of Technology Assessment in Health Care, 12, 405-415.

Vostanis, P., Meltzer, H., Goodman, R., \& Ford, T. (2003). Service utilization by children with conduct disorders: Findings from the GB national study. European Child \& Adolescent Psychiatry, 12, 231-238.

Zwaanswijk, M. (2005). Consultation for and identification of child and adolescent psychological problems in Dutch general practice. Family Practice, 22, 498-506. 